\title{
ROLE OF NT-PRO BNP LEVELS AS A MARKER OF EARLY AND LATE RECURRENCE IN PATIENTS SUBMITTED TO ATRIAL FIBRILLATION ABLATION WITH NORMAL VENTRICULAR FUNCTION.
}

\section{Fabricio Vassallo*, Lucas Luis Meigre, Christiano Cunha, Eduardo Serpa, Hermes Carloni, Aloyr Simões Jr., Flávia Pezzin, Karla Meira, Alberto Nogueira Jr., Orly Lacerda Jr., Walter Batista Jr. and Dalton Hespanhol.}

Department of Electrophysiology of Instituto de Cardiologia do Espirito Santo, Vitoria, Brazil and Department of Cardiology of Hospital Santa Rita de Cassia Vitoria, Brazil.

\section{Email address:}

Fabricio Vassallo: fabricio@arritmiaes.org.

${ }^{*}$ Corresponding author

\section{To cite this article:}

Vassallo F, Meigre LL, Cunha C et al. Role of NT-proBNP as a Marker of Early and Late Recurrence in Patients Submitted to Atrial Fibrillation Ablation with Normal Ventricular Function. Cardiology and Cardiovascular Research. Vol. x, No. x, 2020, pp. x-x. doi: 10.11648/j.ccr.Xxxxxxx.xx.

Received: MM DD, 20; Accepted: MM DD, 20; Published: MM DD, 20.

\begin{abstract}
BACKGROUND: Levels of NT-pro BNP has diagnostic and prognostic correlation in patients with heart failure. It is also described as a possible marker of atrial myocardial disease in patients with normal ventricular function associated with atrial fibrillation (AFib). Retrospective and prospective studies have shown that their high dosage prior and few months after AF ablation may be a risk factor for recurrence. OBJECTIVE: Determine if in patients submitted to first AFib ablation the previous levels of NT-pro BNP and at 6 and 12 months after the procedure the modification in these levels by the restoring and maintenance of sinus rhythm can identify patients at higher risk of recurrence of atrial tachyarrhythmias. METHODS AND RESULTS: From June 2015 and June 2017 we sequentially began the NT-pro BNP serial dosing in patients with paroxysmal and persistent AFib with preserved ventricular function. Levels were in the previous week, 6 and 12 months after the procedure. We prospectively analyzed 73 patients submitted to first time ablation of atrial fibrillation. In pre-procedure set 33 patients had elevated concentrations. Of these $15(45.5 \%)$ remained elevated with a $40 \%$ recurrence rate at 12 -months compared to $5.5 \%$ for those which normalized the levels. On the other hand, we had 40 patients that we considered normal NT-pro BNP levels before ablation. Of these 15 (37.5\%) do not had a descent of more than $50 \%$ from baseline levels had recurrence rates of $33.3 \%$ at 12 months. The remaining $25(62.5 \%)$ who show drops $>50 \%$ of NT-pro BNP recurrence was of only $8 \%$. Patients who had high concentrations of NT-pro BNP or who did not present a significant decrease in these levels were, respectively, 2.25 and 2.28 times more likely to present atrial arrhythmias recurrences after catheter ablation. CONCLUSION: Our data showed that serial levels of NT-pro BNP in patients with atrial fibrillation and normal ejection fraction might identify those at higher risk of recurrence after successful catheter ablation.
\end{abstract}

Keywords: biomarkers, NT-pro BNP, catheter ablation, atrial fibrillation, atrial flutter and recurrence. 


\section{Cardiology and Cardiovascular Research}

2019; X(X): XX-XX

http://www.sciencepublishinggroup.com/j/ccr

doi: $10.11648 /$ j.ccr.2020XXXX.XX

ISSN: 2578-8906 (Print); ISSN: 2578-8914 (Online)

\section{Introduction and Objective:}

Brain Natriuretic Peptide (BNP) has been identified and described since 1988 in pig brains and has

structural and functional similarity to another hormone, the Atrial Natriuretic Peptide (ANP). Initially,

its form of investigation was with the mature form of BNP, BNP-32, passing after the dosage of the amino-terminal form of BNP, the NT-pro BNP [19].

Initial research has been directed at correlating high levels of the hormone as more advanced forms of heart failure because the secretion of larger quantities is in the ventricles. The main diagnostic tools for its use were heart failure, asymptomatic systolic dysfunction [16], diastolic dysfunction, right ventricular disorders and as an etiological diagnosis of dyspnea [12]. Associated with these factors, the prognostic values and therapeutic potentials of the hormone were also documented.

In other circumstances such as AFib which is characterized primarily by electrical remodeling and atrial contractility deterioration the inappropriately rapid ventricular response, loss of the atrial contribution to the cardiac output, and atrial overloading lead to neurohormonal system activation and elevation of ANP and BNP [20] (figure 1). These levels have been demonstrated that after sinus rhythm achievement by successful current cardioversion and MAZE procedures droop to normal $[15,17]$.

AFib ablation with pulmonary vein isolation (PVI) for paroxysmal and persistent types has been described as a curative procedure [10]. In these cases, sequence levels of NTpro BNP pre and post-procedure as a marker of success and consequently recurrence has not been described.

In this descriptive pilot study, we targeted to correlate the serial levels of NT-pro BNP with the success of patients with normal cardiac function who done PVI for treatment of AFib.

\section{Methods:}

\subsection{Participants and Study Settings:}

We prospectively analyzed between June 2015 and June 2017 73 patients were divided in two groups according to the NTpro BNP levels into two groups denominated Group A for patients with abnormal NT-pro BNP levels and Group B for those with normal NT-pro BNP levels. These were symptomatic patients, with paroxysmal or persistent AFib with preserved left ventricular ejection fraction and who were submitted to a first-time procedure. Definition of the types of AFib was described previously elsewhere [10].

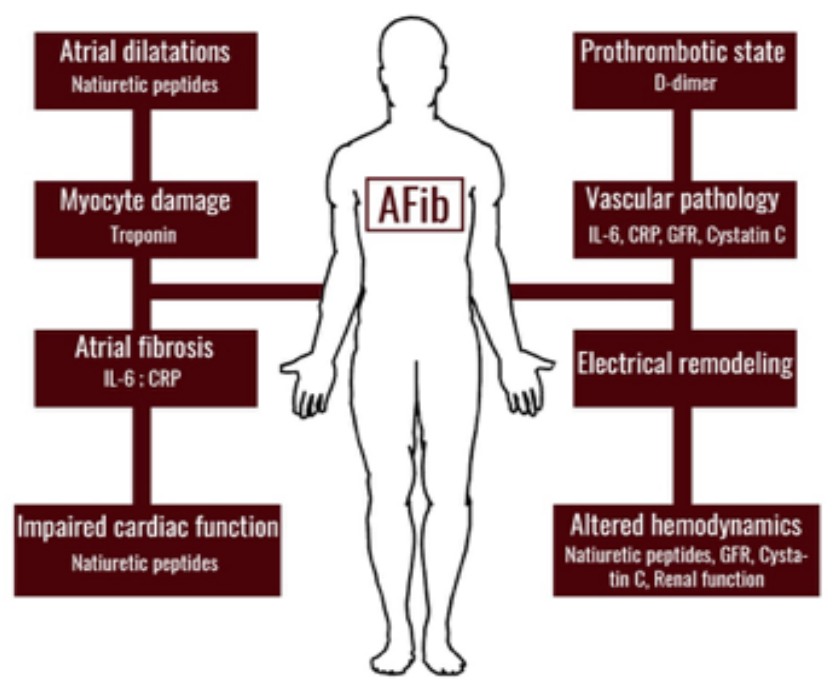

Figure 1: Atrial fibrillation and the pathophysiological changes associated with it (IL-6 Interleucin 6, CRP C Reactive Protein, GFR Growth Factor Releasing Hormone).

Protocol was collecting blood samples to dosage the levels of NT-pro BNP one week previous of the ablation, 6 and 12 months after the procedure. All patients had antiarrhythmic drugs suspended 5 half-lives before procedure, except for amiodarone that were maintained, and after 90 days postablation. Recurrence was defined as clinical symptomatic atrial fibrillation, flutter or tachycardia documented by 12-lead electrocardiogram or an asymptomatic 10 minutes or more of these arrhythmias on the 24 hours Holter monitoring. Clinical and cardiovascular features as anticoagulants and antiarrhythmics drugs are described in Tables 1 and 2 respectively.

On all patients of the study we had NT-pro BNP levels at 6 months and at 12 months that we called the final recurrence (FR) rate and the normalization rate (NR), considering the 
patients who presented recurrence at 6 months post ablation but showed normalization of the rhythm at the final of the study.

\subsection{Catheter Ablation Procedure:}

All patients were successfully submitted to antral isolation of the pulmonary veins [18]. Patients with previous diagnosis of atrial flutter was also treated at the end of the PVI. Procedures were performed in sinus rhythm. On the day of the procedure a total of 27 (36.98\%) patients who were atrial fibrillation or flutter were submitted to electrical cardioversion. At the end of the procedure we made in all patients a challenge of $12 \mathrm{mg}$ of Adenosine for each of the four pulmonary veins to seek for dormant veins and vein reconnection $[6,19]$. We used the Flexibility Catheter with 30 Watts of power and $30 \mathrm{ml} / \mathrm{min}$ irrigation with IBI T9-1500 radiofrequency generator and the support of EnSite Velocity electroanatomic mapping, Intracardiac Echocardiography with ViewFlex catheter, all of which belongs to St Jude Medical ${ }^{\mathrm{TM}}$ (St Jude Medical / Abbott - USA) portfolio.

All patients received esophageal temperature monitoring as described in a previous study [8].

Table 1: Patients clinical features (group A and B).

\begin{tabular}{l|ll}
\hline Clinical Features: & Group A & Group B \\
\hline Gender (male) -n\% & $20(60.6 \%)$ & $26(65 \%)$ \\
Age years (Min/Max) & $65(38 / 83)$ & $56(26 / 70)$ \\
AFIB type - n (\%): & $18(54.5 \%)$ & $28(70 \%)$ \\
Paroxysmal & $15(45.5 \%)$ & $12(30 \%)$ \\
Persistent & $61.2(50 / 68)$ & $67.2(62 / 78)$ \\
Ejection Fraction X \% (Min/Max) & $45.2(33 / 56)$ & $38.7(28 / 49)$ \\
LA Diameter Xmm (Min/Max) & $19.3(11 / 31)$ & $13(8 / 22)$ \\
Time with AFIB X months & & \\
(Min/Max) & $26(78.8 \%)$ & $24(60 \%)$ \\
Arterial Hypertension N (\%) & $5(15.1 \%)$ & $6(15 \%)$ \\
Coronary disease N (\%) & $10(30.3 \%)$ & $8(20 \%)$ \\
Diabetes Mellitus (DM) N \% & $4(12.1)$ & $4(10 \%)$ \\
Stroke / TIA N (\%) & $2(0$ to 6) & $2(0$ to 6$)$ \\
CHADSVASC - X (Min/Max) & & 0.95 \\
\multicolumn{2}{c}{ P Value (for all) }
\end{tabular}

\subsection{Informed Consent and Ethical Considerations:}

All patients signed the informed consent form according to the institution's standards that follow national and international patterns [4,21]. The study was approved by the Human
Research Ethics Committee of the Institution.

\subsection{NT-pro BNP Levels:}

Blood samples for NT-pro BNP concentrations were performed with peripheral vein dosing one week prior to ablation and at 6 and 12 months after the procedure. As there are variations in the reference of normality of the biomarker that include age and sex and being the average age of the study 60 years, we adopt as normal values a limit up to $200 \mathrm{pg} / \mathrm{dl}$, as it was reference in series of other studies [14,15]. The dosage method was of ELFA with apparatus Mini Vidas Automated Immunoassay Analyzer by bioMérieux.

\begin{tabular}{ll}
\hline Medications Used* - N (\%) & Groups A and B (N=73) \\
\hline Apixaban & $6(8.2 \%)$ \\
Dabigatran & $40(54.8 \%)$ \\
Rivaroxaban & $20(27.4 \%)$ \\
Warfarin & $7(9.6 \%)$ \\
Amiodarone & $34(46.6 \%)$ \\
Propafenone & $30(41 \%)$ \\
Sotalol & $9(12.3 \%)$ \\
Beta-blockers & $18(24.6 \%)$ \\
\multicolumn{2}{c}{ * All medications } \\
\multicolumn{1}{c}{ suspended after 90 days } \\
$\quad$ post-procedure
\end{tabular}

Table 2: Medications used: Anticoagulants and Antiarrhythmics Drugs.

\subsection{Pre-Ablation Echocardiogram:}

All patients underwent transesophageal echocardiography predicting the procedure. Thrombus exclusion, left atrial diameter measurements and left ventricular function through the ejection fraction were performed between 24 and 72 hours prior to ablation. Two-dimensional echocardiograms were performed in the parasternal long- and short-axis views and apical 4- and 2-chamber views. Standard two-dimensional measurements (LV end diastolic and end-systolic dimensions, ventricular septal and posterior wall thickness) were obtained with M-mode quantification. Ejection fraction was calculated by Teicholz method. For the evaluation of irregular rhythms at the time of echocardiographic study, ten consecutive cardiac cycles were recorded for the Doppler echocardiographic assessment and the results from 5 cardiac cycles, excluding the longest and shortest cardiac cycles, were averaged [13]. The patients who were on atrial fibrillation the diastolic dysfunction was not analyzed. The echocardiograms were 
made by GE Vivid 7 (GE Healthcare-USA) and Philips CX50 (Philips-USA).

\subsection{Rhythm Monitoring:}

The follow-up of patients was made with electrocardiogram on hospital discharge, up to 15 days, 1, 3, 6 and 12 months after ablation. The 24-hour Holter monitoring at 6 and 12 months after the procedure.

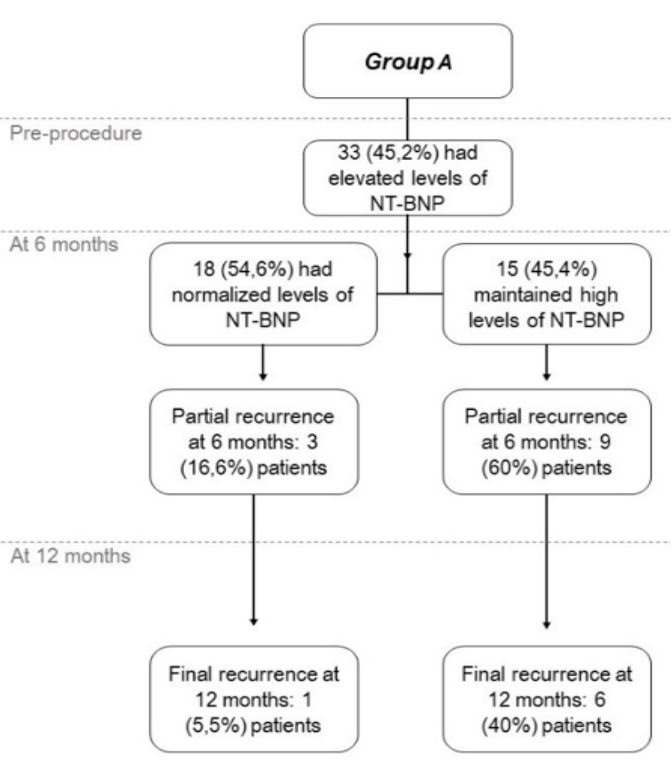

Figure 2: Group A algorithm.

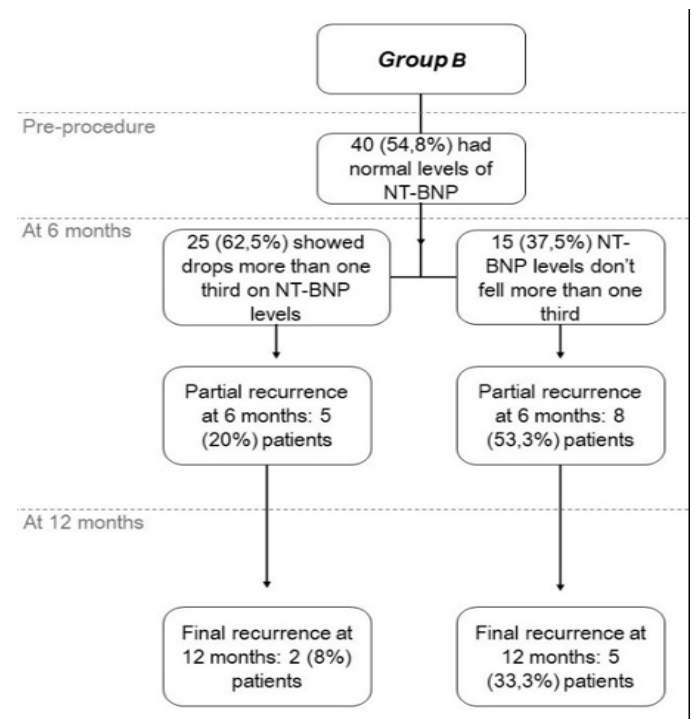

Figure 3: Group B algorithm.

Patients were encouraged to report any complaints suggestive of arrhythmia as well as to seek out our reference service including the clinic or the Hospital for electrocardiogram performance and clinical evaluation. As all patients was submitted to ablation for having symptomatic AFib we considered recurrence if the patient had suggestive symptoms with an electrocardiogram or Holter tracings of atrial tachyarrhythmias (atrial tachycardia, atypical atrial flutter or AFib). In the 24 hours Holter monitoring when patients do not had reference of any symptom recurrence was considered with atrial tachycardia for more than 10 minutes.

\section{Statistical Analysis:}

Statistical analysis used the $t$ test for correlation between averages of two groups and the odds ratiotest to identify the risk of recurrence between groups considering three important factors (high level of NT-BNP, resistance in decreasing NTBNP levels and recurrence). All tests were performed using BioEstat 5.0 statistical software.

\section{Results:}

As described before we divide the results into two groups.

Group A consisted of 33 patients who had abnormally high levels of NT-pro BNP pre-ablation with an average of $448.2 \pm 187 \mathrm{pg} / \mathrm{dl}$ since the normal level was accepted as $200 \mathrm{pg} / \mathrm{dl}$ in this study $[7,14,15]$. After the procedure on the 6 months NT-pro BNP in 18 patients presented significant drops to normal levels with reductions to average levels of $178 \pm 59 \mathrm{pg} / \mathrm{dl}$ and $166 \pm 32 \mathrm{pg} / \mathrm{dl}$ at 6 and 12 months. In this subgroup we documented the presence recurrences rates at 6 months and 12 months of $16.6 \%$ and 5,5\% respectively. On the 15 patients who maintained high levels of NT-BNP with $352.1 \pm 104 \mathrm{pg} / \mathrm{dl}$ and $279.6 \pm 55 \mathrm{pg} / \mathrm{dl}$ at 6 and 12 months after ablation we saw that the recurrence rate at 6 and 12 months was $60 \%$ and $40 \%$ respectively (Figure 2). In group B, 40 patients presented normal levels with an average of $182 \pm 51 \mathrm{pg} / \mathrm{dl}$ and even in this group we also observed differences between patients with higher or lower rates of atrial tachyarrhythmias after ablation. In a sub analysis, the first subgroup of 25 patients who presented a significant decrease of more than $51,65 \%$ that we called a drop in more than one-half in relation to the previous NT-pro BNP levels recurrence rates were much lower with $20 \%$ (5 patients) and $8 \%$ ( 2 patients) at 6 and 12 months respectively. The levels of NT-pro BNP at 6 months were $114 \pm 33 \mathrm{pg} / \mathrm{dl}$ and $88 \pm 28 \mathrm{pg} / \mathrm{dl}$ at 12 months. The partial recurrence was $20 \%$ and final recurrence of $8 \%$. In the subgroup of 15 patients with falls 
below one-half from baseline we observed that recurrence rates of atrial arrhythmias were higher at 6 and 12 months (Figure 3). These indices were $40 \%$ and $33 \%$ for partial, 6 months, and final recurrence (FR), 12 months, respectively. The average dosages of NT-BNP were $142 \pm 39 \mathrm{pg} / \mathrm{dl}$ and $130 \pm 31 \mathrm{pg} / \mathrm{dl}$ at 6 and 12 months.

These findings tell us an important data. In both groups patients that do not show falls in the NT-pro BNP levels after ablation have a significant higher recurrence rate of atrial tachyarrhythmias $(\mathrm{P}<0,0001)$, in partial at 6 months, and final at 12 months follow-up. When we used the odds ratio test the data collected at the end of the study showed us that in the Group A patients that maintained abnormal values of the biomarker had 2.25 more chances of an atrial tachyarrhythmia when compared to those who normalized it. We also see similar results in the Group B with a 2.28 higher chance of arrhythmia recurrence for those with no significant drop after ablation.

\section{Discussion:}

According to our best knowledge this article was the first to analyze and perform serial levels of NT-pro BNP and to evaluate its correlations with recurrence at 6 and 12 months in patients with normal ventricular function post-ablation of atrial fibrillation. In other papers the authors do not divided the patients in groups with normal and elevated levels of the biomarker a circumstance that we did in this article and which we also think that is very important since in the group of normal levels of BNP we have different behaviors since patients that had a more prominent drop have significant lower rates of recurrence.

Previous studies published with NT-pro BNP dosages between 3- and 6-months post-procedure demonstrate that isolation of pulmonary veins effectively leads to adequate rhythm and heart rate control and as a result there are a drop to normal levels and there is thus correlation with the success of the intervention [12]. This and other studies [1,2,5,9] as well as our hypothesis, is that NT-pro BNP is a reliable marker of myocardial injury in patients with atrial fibrillation in patients without left ventricular ejection fraction reduction and that control of the ventricle heart rate would bring this hormone to normal levels.

Therefore, we believe that with restoration of sinus rhythm and its maintenance over the months NT-pro BNP levels become lower even in patients who did not present high and/or abnormal values prior to the procedure. We also made a sub analysis of the patients with normal levels of this preprocedural biomarker. We observed that when there was a decrease of more than half of these values at 6 and 12 months, we were able to identify patients with a higher or lower risk of recurrence, which may be directly related to greater or less burden of atrial tachyarrhythmias, respectively.

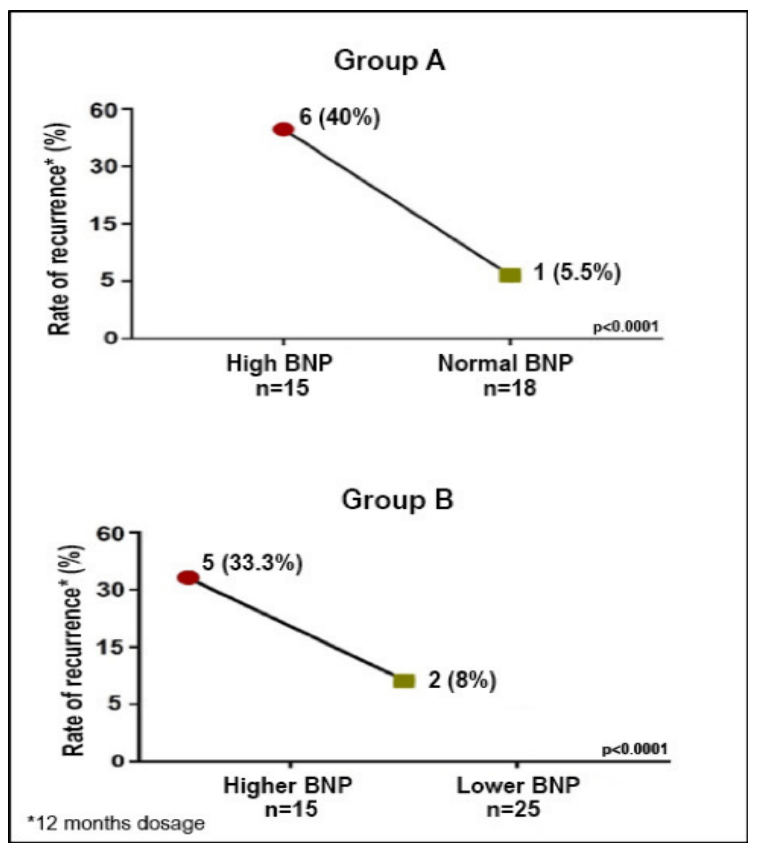

Figure 4: Final recurrence rates in Groups $A$ and $B$ (P value of $<\mathbf{0 . 0 0 0 1}$ for both groups).

In our study we also observed a higher incidence of atrial tachyarrhythmias including atrial fibrillation, flutter and atrial tachycardia when we performed 24 hours Holter at 6 than at 12 months, remembering that all patients at this time were off antiarrhythmics since these medications were suspended at 3 months after ablation. This fact can be explained by a common effect that we observed in at least $30 \%$ of patients undergoing this type of intervention that another author and ourselves attribute to the local inflammatory process of radiofrequency that can last up to 3 months of the procedure. In this pilot study we can discuss if this blanking period can lasts more than 3 months and can goes at least at 6 months post-ablation since we had a significant drop in recurrence rate at the end of the study. However even considering this blanking period that could be a bias in our study our results at the end of the study 
Vassallo F et al. Role of NT-proBNP as a Marker of Early and Late Recurrence in Patients Submitted to Atrial Fibrillation Ablation with Normal Ventricular Function

are maintained with greater recurrence of arrhythmias in patients with higher levels of the biomarker studied when compared to baseline. The present study may open a discussion for an individualized and very simple way to make a practical follow-up in the post-ablation of atrial fibrillation identifying patients with a higher risk of recurrences.

\begin{tabular}{l|ll}
\hline Group A (33 patients) & Group A1 (15) & Group A2 (18) \\
\hline BNP LEVELS & ABNORMAL & NORMAL \\
Partial Recurrence (6 months) & $9(60 \%)$ & $3(16.6 \%)$ \\
Final Recurrence (12 months) & $6(40 \%)$ & $1(5.5 \%)$ \\
Normalization Rate & $3(33.3 \%)$ & $2(66.6 \%)$ \\
\multicolumn{1}{c|}{ P VALUE } & $\mathrm{p}<0.0001$ & \\
& &
\end{tabular}

Table 3: Recurrence rates in group A (patients with high NT-BNP levels). Group A1: patients maintained elevated levels of NT-BNP. Group A2: patients who normalized NT-BNP levels.

\begin{tabular}{l|ll}
\hline GROUP B (40 patients) & Group B1 (15) & Group B2 (25) \\
\hline BNP LEVELS & DROP $<\mathbf{5 0 \%}$ & DROP $>\mathbf{5 0 \%}$ \\
Partial Recurrence (6 months) & $8(53.5 \%)$ & $5(20 \%)$ \\
Final Recurrence (12 months) & $5(33.3 \%)$ & $2(8 \%)$ \\
Normalization Rate & $3(37.5 \%)$ & $3(60 \%)$ \\
\multicolumn{1}{c}{ P VALUE } & $\mathrm{p}<0.0001$ & \\
& &
\end{tabular}

Table 4: Recurrence rates in group B (patients with normal NT-BNP levels). Group B1: patients maintained elevated levels of NT-BNP. Group B2: patients who normalized NT-BNP levels.

\section{Study Limitations:}

Our study did not aim to determine if variations between atrial fibrillation types being paroxysmal or persistent could affect the outcome since previous studies had previously determined that restoration of sinus rhythm independently from the AFib type would improve NT-pro BNP levels. In addition, only 27 (37\%) patients were in different rhythms of the sinus in the day of the procedure and maybe in the day of the collection of blood samples to determine NT-pro BNP levels, which contributes to higher levels of this biomarker and to the belief that this data the type of AFib did not affect our results, but the burden of the of tachyarrhythmias during the study does enhance the levels of this biomarker.
We also observed another factor that we did not relate, which was the size and volume of the left atrium, because just as the type of AFib can also be a bias in view of the possibility of changes in the levels of this biomarker. As the study was performed only in patients with preserved left ventricular function, we did not perform sub analyses in this subgroup of patients according to left atrial diameter, normal versus augmented.

We must also describe that patients with elevated levels of NTpro BNP at 6 months could have normal or lower levels at the dosage of 12 months since our aim was not to make sequential analyses of each individual included in the trial. In addition, it should be emphasized that the expression of NT-pro BNP is higher in the ventricles and the lower myocardial mass of the atrium may be limited in the dosages of this biomarker in this type of situation and perhaps the use of NT-pro ANP results in more reliable results $[2,11]$.

\section{Conclusion:}

This descriptive observational pilot study shows that serial dosages of NT-pro BNP in patients submitted to first time catheter ablation of atrial fibrillation and with normal ejection fraction identify individuals at higher risk of recurrence of atrial tachyarrhythmias at 6 and 12 months, markedly those who has high pre-ablation levels and which remains elevated after the procedure.

\section{Disclosure:}

None.

\section{Acknowledgements:}

The support team composed by Christiane Amaral and Vanessa Rodrigues and the Bio Medics Edevaldo Ferreira and Marcel Burguês for the dedication and support in data collection and conclusion of this clinical research. 


\section{References:}

[1] Beuttner P, Schumacher K, Dinov B, Zeynalova S, Sommer P, Bollmann A, Husser D, Hindricks G, Kornej J. Role of NT-pro ANP and NT-pro BNP in patients with atrial fibrillation: Association with atrial fibrillation progression phenotypes. Heart Rhythm 2018; 15:1132-1137. https://doi.org/10.1016/j.hrthm.2018.03.021

[2] Charitakis E, Walfridsson $\mathrm{H}$ and Alehagen U. ShortTerm Influence of Radiofrequency Ablation on NT-proBNP, MR-proANP, Copeptin, and MR-proADM in Patients with Atrial Fibrillation: Data From the Observational SMURF Study. J Am Heart Assoc. 2016;5: e003557. https://doi.org/10.1161/JAHA.116.003557

[3] Macle L, Khairy P, Weerasooriya R, Novak P, Verma A, Willems S, Arentz T, Deisenhofer I, Veenhuyzen G, Scavée C, Jaïs P, Puererfellner H, Levesque S, Andrade JG, Rivard L, Guerra PG, Dubuc M, Thibault B, Talajic M, Roy D, Nattel S. Adenosine-guided pulmonary vein isolation for the treatment of paroxysmal atrial fibrillation: an international, multicentre, randomised superiority trial. Lancet. 2015 Aug 15;386 (9994):672-9. https://doi.org/10.1016/S01406736(15)60026-5

[4] Ministry of Health - MS National Agency of Sanitary Surveillance - ANVISA RESOLUTION OF THE BOARD OF DIRECTORS - DRC No. 9, OF FEBRUARY 20, 2015 (Published in the DOU no. 41, of March 3, 2015).

[5] Pillarisetti J, Reddy J, Biria M, Ryschon K, Nagarajan D, Murray C, Atkins D, Bommana S, Reddy MY, Di Biase L, Pimentel R, Berenbom L, Dawn B, Natale A, Lakkireddy D. Elevated brain natriuretic peptide level in patients undergoing atrial fibrillation ablation: is it a predictor of failed ablation or a mere function of atrial rhythm and rate at a point in time? J Interv Card Electrophysiol Aug 2014, Vol. 40 Issue 2, p161-168. https://doi.org/10.1007/s10840-0149898-7

[6] McLellan AJA, Kumar S, Smith C, Morton JB, Kalman JM, Kistler PM. The role of adenosine following pulmonary vein isolation in patients undergoing catheter ablation for atrial fibrillation: a systematic review. J. Cardiovasc. Electrophysiol. $2013 \quad$ Jul;24 (7):742-51. https://doi.org/10.1111/jce.12121

[7] Kornej J, Apostolakis S, Bollmann A, and Lip GYH. The Emerging Role of Biomarkers in Atrial Fibrillation. Canadian Journal of Cardiology $29 \quad$ (2013) 1181e1193. https://doi.org/10.1016/j.cjca.2013.04.016

[8] Leite LR, Santos SN, Maia H, Henz BD, Giuseppin F, Oliverira A, Zanatta AR, Peres AK, Novakoski C, Barreto JR, Vassalo F, d'Avila A and Singh SM. Luminal Esophageal Temperature Monitoring with a Deflectable Esophageal Temperature Probe and Intracardiac Echocardiography May Reduce Esophageal Injury During Atrial Fibrillation Ablation Procedures. Results of a Pilot Study. Circ Arrhythm Electrophysiol. 2011; 4:149-156. https://doi.org/10.1161/CIRCEP.110.960328

[9] Danicek V, Theodorovich N, Bar-Achaim S, Miller A, Vered Z, Koren-Morag N, Uriel N, Czuriga I, Shopen A, Brantiss $N$ and Kaluski E. Sinus Rhythm Restoration after Atrial Fibrillation: The Clinical Value of N-Terminal Pro-BNP Measurements. PACE 2008; 31:955-960. https://doi.org/10.1111/j.1540-8159.2008.01121.x

[10] Calkins H, Brugada J, Packer DL, Cappato R, Chen S-A, Crijns HJG et. al. HRS/EHRA/ECAS Expert Consensus Statement on Catheter and Surgical Ablation of Atrial Fibrillation: Recommendations for Personnel, Policy, Procedures and Follow-Up. A report of the Heart Rhythm Society (HRS) Task Force on Catheter and Surgical Ablation of Atrial Fibrillation Developed in partnership with the European Heart Rhythm Association (EHRA) and the European Cardiac Arrhythmia Society (ECAS); in collaboration with the American College of Cardiology (ACC), American Heart Association (AHA), and the Society of Thoracic Surgeons (STS). Endorsed and Approved by the governing bodies of the American College of Cardiology, the American Heart Association, the European Cardiac Arrhythmia Society, the European Heart Rhythm Association, the Society of Thoracic Surgeons, and the Heart Rhythm Society. Europace (2007) 9, 335-379. 
Vassallo F et al. Role of NT-proBNP as a Marker of Early and Late Recurrence in Patients Submitted to Atrial Fibrillation Ablation with Normal Ventricular Function

https://doi.org/10.1093/europace/eum120.

[11] Yamada T, Murakami Y, Okada T, Okamoto M, Shimizu T, Toyama J, Yoshida Y, Tsuboi N, Ito T, Muto M, Kondo T, Inden Y, Hirai M, and Murohara T. Plasma Atrial Natriuretic Peptide and Brain Natriuretic Peptide Levels After Radiofrequency Catheter Ablation of Atrial Fibrillation. Am J Cardiol 2006;97: 1741-1744. https://doi.org/10.1016/j.amjcard.2005.12.071

[12] Berdague P, Caffin PY, Barazer I, Vergnes C, Sedighian S, Letrillard S, Pilossof R, Goutorbe F, Piot and Reny J-L, CH Beziers and CHU Montpellier. Use of N-terminal prohormone brain natriuretic peptide assay for etiologic diagnosis of acute dyspnea in elderly patients. Am Heart J 2006; 151:690- 8. https://doi.org/10.1016/j.ahj.2005.04.004

[13] Lang RM, Bierig M, Devereux RB et al (2005). Recommendations for chamber quantification: a report from the American Society of Echocardiography's guidelines and standards committee and the chamber quantification writing group, developed in conjunction with the European Association of echocardiography, a branch of the European Society of Cardiology. J Am Soc Echocardiogr 18:1440-1463. https://doi.org/10.1016/j.euje.2005.12.014

[14] Wright SP, Doughty RN, Pearl A, Gamble GD, Whalley GA, Walsh HJ, Gordon G, Bagg W, Oxenham H, Yandle T, Richards $\mathrm{M}$ and Sharpe N. Plasma Amino-Terminal Pro-Brain Natriuretic Peptide and Accuracy of Heart-Failure Diagnosis in Primary Care. A Randomized, Controlled Trial. J Am Coll Cardiol 2003; 42:1793-800. doi:10.1016/j.jacc.2003.05.011

[15] Lemos JA, McGuire DK, Drazner MH. B-type natriuretic peptide in cardiovascular disease. LANCET • Vol 362 • July 26, 2003. https://doi.org/10.1016/S0140-6736(03)13976-1.

[16] Watanabe M, Murakami M, Furukawa H, Nakahara H, Tanaka H, Sunamori M. Decreased plasma brain natriuretic peptide levels after a successful Maze procedure. J Heart Valve Dis 2003; 12:287-291.
[17] Oral H, Knight BP, Tada H, Ozaydin M, Chugh A, Hassan S, Scharf C, Lai SWK, Greenstein R, Pelosi F, et al. Pulmonary vein isolation for paroxysmal and persistent atrial fibrillation. Circulation 2002;105: 1077-1081. doi:

10.1161/hc0902.104712

[18] Wozakowska-Kaplon B, Opolski G. Atrial natriuretic peptide level after cardioversion of chronic atrial fibrillation. Int $\mathrm{J} \quad$ Cardiol 2002; 83:159-165. https://doi.org/10.1016/S0167-5273(02)00066-9

[19] P. J. Hunt, A. M. Richards, M. G. Nicholls, T. G. Yandle, R. N. Doughty and E. A. Espiner. Immunoreactive aminoterminal pro-brain natriuretic peptide (NT-PROBNP): a new marker of cardiac impairment. Clinical Endocrinology (1997) 47, 287-296. https://doi.org/10.1046/j.13652265.1997.2361058.x

[20] Roy D, Paillard F, Cassidy D, Bourassa MG, Gutkowska J, Genest J, Cantin M. Atrial natriuretic factor during atrial fibrillation and supraventricular tachycardia. J Am Coll Cardiol 1987; 9:509 -514. DOI: 10.1016/S07351097(87)80042-6

[21] Rickham PP. Code of Ethics of the World Medical Association. Declaration of Helsinki. Human experimentation. Br Med J 1964; 2:177. 